\title{
Recurrent Synovial Sarcoma
}

National Cancer Institute

\section{Source}

National Cancer Institute. Recurrent Synovial Sarcoma. NCI Thesaurus. Code C8827.

The reemergence of synovial sarcoma after a period of remission 